\section{Phytochemical and Yield Variation among Iranian Achillea millefolium Accessions}

\author{
Mostafa Farajpour and Mohsen Ebrahimi ${ }^{1}$ \\ Department of Agronomy and Plant Breeding, College of Abourihan, \\ University of Tehran, Tehran, Iran
}

\begin{abstract}
Amin Baghizadeh
Department of Biotechnology, Institute of Science and High Technology and Environmental Sciences, Graduate University of Advanced Technology, Kerman, Iran
\end{abstract}

\section{Mostafa Aalifar \\ Young Researchers Club, Hamedan Branch, Islamic Azad University, Hamedan, Iran}

Additional index words. Achillea millefolium, PCA, cluster analysis, Phytochemical variability, Iran

\begin{abstract}
Chemical composition and essential oil yields from aerial parts of 31 Iranian Achillea millefolium accessions, each collected from their natural habitats of Iran and grown together in field conditions, were investigated. The concentrations of the hydrodistilled essential oils ranged from $0.03 \%$ to $0.39 \%$. Gas chromatography-mass spectrometry (GC-MS) analysis revealed 50 compounds in the accessions. The main components of the essential oils in Iranian A. millefolium accessions varied in the following ranges: $1,8-C$-Cineole, $1.2-19.8 \%$; $\beta$-thujone, $0.4-55.3 \%$; camphor, $0.6-25.5 \%$; germacrene-D, 2-20.6\%; trans-nerolidol, $0.4-48.1 \%$; isospathulenol, $0.5-36 \%$; and cubenol, 0.1-42.9\%. According to cluster analysis, five chemotypes were obtained as 1,8-Cineole/trans-nerolidol, high cubenol, high germacrene-D/isospathulenol, high camphor/cubenol, and high 1,8-Cineole/ $\beta$-thujone/cubenol. The result of principal component analysis (PCA) indicated that germacrene-D and isospathulenol components were under more genetic control than the other main components. Results revealed a high level of variation of composition and yield of essential oils among the Iranian $A$. millefolium accessions.
\end{abstract}

Achillea millefolium $\mathrm{L}$. is one of the most important medicinal plants because of its diverse medicinal uses including anti-infective, spasmolytic, choleretic, carminative, and antiinflammatory activities (Benedek et al., 2007; Naeini et al., 2009).

It is spread in many regions of Iran. Investigation about the phytochemical components of $A$. millefolium is important for determining therapeutic agents having potential pharmaceutical value (Farnsworth, 1966; Pandith, 2012).

The many accessions of Iranian $\mathrm{A}$. millefolium are known to produce a wide variety of chemical compounds in the essential oils, with the most abundant components identified as chamazulene, germacrene $\mathrm{D}$, sabinene, $\beta$-caryophyllene, p-cymene, bornyl acetate, camphene, $\beta$-pinene, 1,8-Cineole, camphor, ascaridole, linalool, $\alpha$ - and $\beta$-thujone,

Received for publication 23 Dec. 2016. Accepted for publication 7 Apr. 2017.

This study was supported by University of Tehran. We would like to thank Christine L. Kirkpatrick from Department of Chemistry, University of North Carolina at Chapel Hill for suggestions and English editing the article.

${ }^{1}$ Corresponding author. E-mail: Mebrahimi@ut.ac.ir. cis- and trans $\beta$-ocimene, myrcene, limonene, $\gamma$-terpinene, caryophyllene oxide, abisabolol, $\beta$-eudesmol, and $\alpha$-phellandrene (Dehghan and Elmi, 2015; Ebrahimi et al., 2012; Gudaityte and Venskutonis, 2007; Judzentiene, 2016; Sevindik et al., 2016; Stevanovic et al., 2015). In Iran, most studies on A. millefolium have been focused on only a few accessions that are limited to a single geographical area (Afsharypuor et al., 1996; Jaimand et al., 2006; Maz et al., 2013; Mazandarani et al., 2007). Ebrahimi et al. (2012) studied essential oil variation among five Achillea millefolium ssp. elbursensis collected from different ecological regions in Iran. In their study, accessions of subspecies of elbursensis were examined. To the best of our knowledge, there is not a comprehensive study on essential oil components of the plant in Iran.

The objective of this study was to expand the information on the chemical variations in essential oil of $A$. millefolium accessions from different regions in Iran.

\section{Materials and Methods}

Plant materials. Seeds of 37 accessions of A. millefolium were collected from the North- ern, Northwestern, Western, Southern, and central regions of Iran (Table 1) and cultivated in the research farm of College of Abouraihan, University of Tehran, in Spring 2012. Voucher samples were deposited at the Herbarium of Research Institute of Forests and Rangelands Tehran, Iran (Farajpour et al., 2012). The randomized complete block design with three replications was used. First, accessions were cultivated in a greenhouse, and then, when the plant reaches to about $10 \mathrm{~cm}$, they were transferred to the filed. Each accession was sowed in $1 \mathrm{~m}^{2}$ plots in a sandyloam soil. The results of soil analysis of the filed are present in Table 2. Accessions were harvested at $10-20 \%$ flowering stage to obtain essential oils. For GC-MS analysis, the plants from the three replications were mixed. Finally, for each accession one sample was used to GC-MS analysis. Genetic diversity based on morphological, phenological, and molecular markers from these plants were reported in our previous study (Farajpour et al., 2012)

Isolation of essential oils. Aerial parts of A. millefolium accessions were dried at room temperature. Hundred grams of each sample was extracted by hydro-distillation (1:5 biomass:water ratio) in a 2-L Clevenger-type apparatus for $3 \mathrm{~h}$. The oils were collected from the top of the apparatus using syringe. Yields of essential oils were calculated based on air-dried materials.

Composition of essential oils. GC-MS analysis was conducted using a Varian CP3800 GC coupled to a Varian 4000 (Ion trap) mass analyzer. The GC was equipped with a capillary VF-5 fused silica column $(30 \mathrm{~m} \times$ $0.25 \mathrm{~mm}$ i.d., film thickness $0.25 \mu \mathrm{m}$ ), using helium as the carrier gas with constant flow of $1.0 \mathrm{~mL} \cdot \mathrm{min}^{-1}$ and a split ratio of $1 / 50$. The oven temperature was held at $60^{\circ} \mathrm{C}$ for $1 \mathrm{~min}$ and then ramped to $250{ }^{\circ} \mathrm{C}$ at a rate of $3{ }^{\circ} \mathrm{C} /$ min where it was held for $10 \mathrm{~min}$. The injector and detector (FID) temperatures were kept at 250 and $280{ }^{\circ} \mathrm{C}$, respectively. Mass spectra were taken at $70 \mathrm{ev}$ with a mass/ charge range of 35-400.

The chemical composition of the essential oils was determined through calculation of retention indices under temperatureprogrammed conditions for n-alkanes (C6C24) in comparison with the oils on a VF-5 column under the same chromatographic conditions. The compounds were identified by comparison of their mass spectra with those in the Wiley 7 database or with injection of isolated standards. These matches were confirmed by comparison of their retention indices with that of known compounds or with those reported in the literature. For quantification purposes, relative area percentages obtained by FID were used without any correction factor.

Statistical analysis. Cluster and PCA were performed using SPSS v.23, and calculation of correlations was performed using statistical analysis system (SAS) computer software (SAS institute Cary, NC, 1988). In addition, the means scanning electron microscopy of the oils' content were compared 
Table 1. Origins, oil yields, and geographical location of 31 Iranian Achillea millefolium accessions.

\begin{tabular}{|c|c|c|c|c|c|c|c|}
\hline Code & Origin & Elevation $(\mathrm{m})$ & Oil yield (\%) & Accession & Origin & Elevation $(\mathrm{m})$ & Oil yield (\%) \\
\hline$\overline{\mathrm{Am} 1}$ & Markazi, Arak & 1,722 & $0.39^{\mathrm{z}} \pm 0.1$ & Am17 & Fars, Abadeh & 1,992 & $0.03 \pm 0.00$ \\
\hline $\mathrm{Am} 2$ & Golestan, Gorgan & 175 & $0.20 \pm 0.01$ & Am 18 & Gilan, Talesh & 47 & $0.04 \pm 0.03$ \\
\hline Am3 & Hamadan, Hamadan & 1,741 & $0.05 \pm 0.02$ & Am19 & Kordestan, Bijar & 1,912 & $0.06 \pm 0.01$ \\
\hline Am4 & Lorestan, Azna & 1,871 & $0.16 \pm 0.01$ & $\mathrm{Am} 20$ & Hamadan, Hamadan & 1,741 & $0.04 \pm 0.00$ \\
\hline Am5 & Fars, Estahban & 1,767 & $0.03 \pm 0.00$ & Am 21 & Golestan,Minodasht & 140 & $0.16 \pm 0.02$ \\
\hline Am6 & Kordestan, Sanandaj & 1,464 & $0.19 \pm 0.04$ & Am22 & Lorestan, Khoramabad & 1,246 & $0.05 \pm 0.00$ \\
\hline Am7 & Lorestan, Brojerd & 1,620 & $0.07 \pm 0.03$ & Am23 & Isfahan, Chadegan & 2,400 & $0.25 \pm 0.02$ \\
\hline Am8 & Isfahan, Samirom & 2,500 & $0.06 \pm 0.00$ & Am24 & Fars, Shiraz & 1,484 & $0.08 \pm 0.02$ \\
\hline Am9 & Kordestan, Marivan & 1,320 & $0.24 \pm 0.09$ & $\operatorname{Am} 25$ & Isfahan, Kashan & 949 & $0.05 \pm 0.01$ \\
\hline Am10 & Kordestan, Kamyaran & 1,464 & $0.05 \pm 0.02$ & Am26 & Kordestan, Sanandaj & 1,446 & $0.20 \pm 0.02$ \\
\hline Am11 & Markazi, ARAK & 1,722 & $0.04 \pm 0.01$ & Am27 & Tehran, Taleghan & 1,840 & $0.08 \pm 0.02$ \\
\hline Am12 & Lorestan, aligodarz & 2,020 & $0.08 \pm 0.03$ & Am 28 & Golestan, Ramyan & 180 & $0.21 \pm 0.08$ \\
\hline Am13 & Gilan, Rodsar & -18 & $0.05 \pm 0.03$ & Am29 & Gilan, Siahkal & 170 & $0.35 \pm 0.02$ \\
\hline Am14 & Gilan, Siahkal & 29 & $0.06 \pm 0.02$ & Am30 & Ilam, Ilam & 1,381 & $0.22 \pm 0.05$ \\
\hline Am15 & Markazi, Tafresh & 1,880 & $0.09 \pm 0.01$ & Am31 & Golestan, Aliabad & 1,071 & $0.05 \pm 0.00$ \\
\hline Am16 & Kordestan, Bane & 1,503 & $0.22 \pm 0.04$ & \multicolumn{2}{|c|}{ Least significant difference $(0.05)$} & 0.07 & \\
\hline
\end{tabular}

${ }^{\mathrm{z}}$ Mean \pm standard error $(\mathrm{SE})$, the oils $(\mathrm{w} / \mathrm{w})$ were obtained from aerial parts of the plants.

using least significant difference test (Steel and Torrie, 1980).

\section{Result and Discussion}

The essential oils yield. The essential oils yield of A. millefolium (mean values from three replicates) varied in the range from $0.03 \%$ to $0.39 \%$ (Table 1 ). The highest content of essential oils was found in accession collected from Arak, Markazi Province (Am1 accession); it was $0.39 \%$. The lowest amount of essential oil, $0.03 \%$, was distilled from two accessions collected from Fars Province (Am5 and Am17 accessions). The authors found the yields of essential oil in the range of $0.15-0.60 \%$. This result suggests that environmental factors play an important role in the quantity of essential oil yields in Iranian $A$. millefolium accessions as their plants were grown under different time and geographical conditions. However, our accessions had higher essential oil content than Lithuanian A. millefolium samples (in the range of $0.06-0.19 \%$; Gudaityte and Venskutonis, 2007) because of using many accessions from different habitats.

Furthermore, these results showed no obvious relationship between the location of accession and essential oil yield. For example, Am1, Am2, and Am3 with high essential oil yields were collected from the center, north, and west of the country, respectively.

Essential oil composition. The composition of each essential oil of the 31 Iranian $A$. millefolium accessions was analyzed by GCMS (Table 3). A total number of 50 compounds were identified across all accessions. Forty-two of these compounds were observed in Am13 accession. However, 117 compounds were identified in Lithuanian $A$. millefolium samples (Gudaityte and Venskutonis, 2007). These different reports on the number of components among medicinal plants accessions can be due to seasonal and genetic diversity, geographical origin, growth stages, part used of the plants, and postharvest drying (Anwar, 2009). The collected data clearly show the presence of a remarkable phytochemical polymorphism among accessions of A. millefolium in Iran. The main components

Table 2. The result of soil analysis in the present study.

\begin{tabular}{lcccccccccc}
\hline Texture & Sand & Silt & Clay & $\mathrm{K}(\mathrm{mg} / \mathrm{kg})$ & $\mathrm{P}(\mathrm{mg} / \mathrm{kg})$ & Total N $(\%)$ & OC & TNV & $\mathrm{pH}$ & $\mathrm{Ec} \mathrm{ds} / \mathrm{m}$ \\
\hline Sandy loam & 64 & 16 & 20 & 500 & 18 & 0.2 & 2.8 & - & 6.8 & $<6$ \\
\hline
\end{tabular}

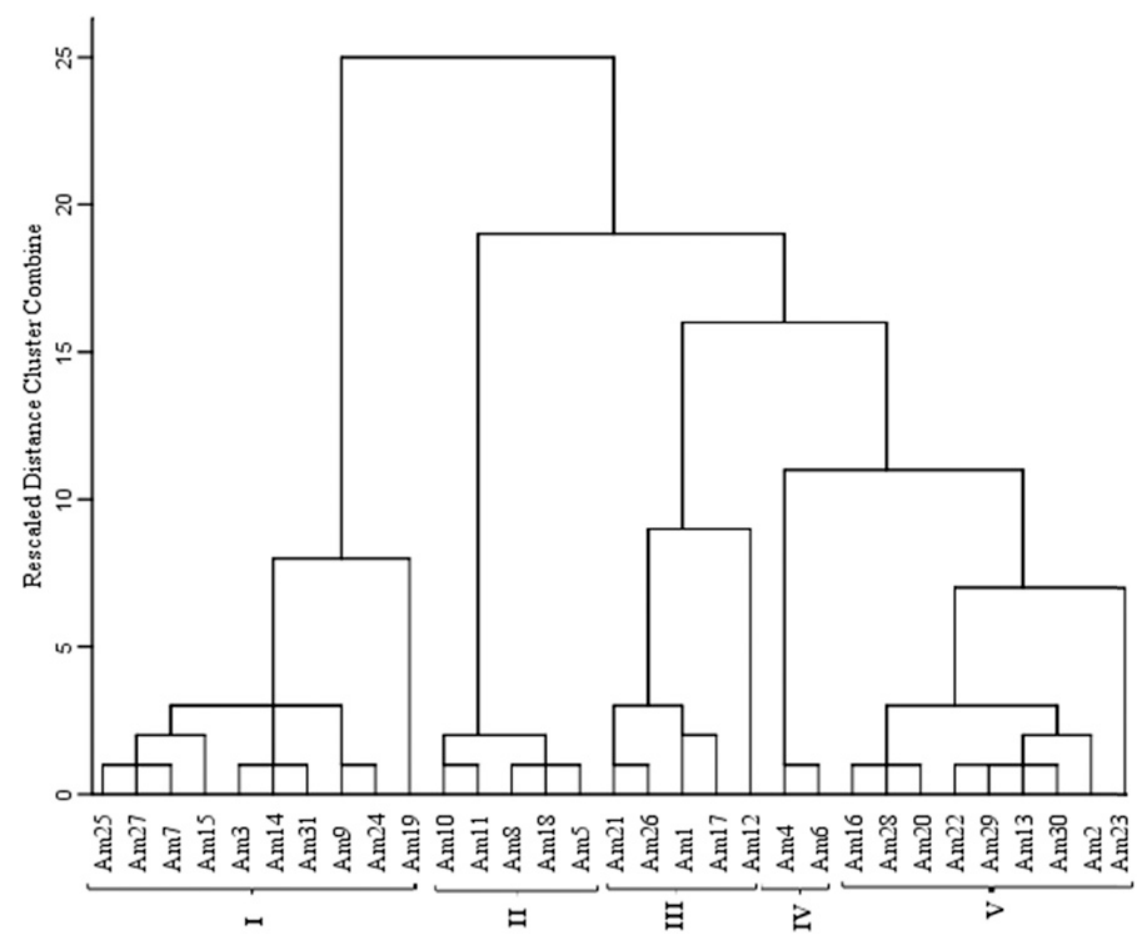

Fig. 1. Dendrogram of 31 Iranian A. millefolium accessions, according to the composition of their major essential oils using Ward's minimum variance.

of the essential oils in Iranian A. millefolium accessions varied in the following ranges: 1,8-Cineole (1.2-19.8\%), $\beta$-thujone $(0.4$ $55.3 \%)$, camphor $(0.6-25.5 \%)$, germacreneD (2-20.6\%), transnerolidol (0.4-48.1\%), isospathulenol $(0.5-36 \%)$, and cubenol (0.1-42.9\%). However, some accessions had a high percentage of one of the individual compounds that did not make the top 7 list. Am17 accession was rich in limonene (15\%); Am1 and Am26 accessions were rich in $\gamma$-terpinene (49.4 and $22.4 \%$, respectively) and calacorene (25.1\% and $10.7 \%$, respectively);
Am6 and Am29 accessions were rich in pinocarvone (18.7\% and $15.8 \%$, respectively); Am15, Am16, and Am17 accessions were rich in borneol $(10.6 \%, 10.5 \%$, and $17.8 \%$, respectively); Am3 accession was rich in caryophyllene-oxide (11.9\%); and Am21 accession was rich in $\beta$-eudesmol $(15.6 \%)$. All the accessions had 1,8-Cineole and camphor components. cubenol was the most abundant component in seven essential oil accessions, 1,8-Cineole was the major component in six accessions, $\beta$-thujone and transnerolidol in four accessions, camphor in 
Table 3. Chemical composition of essential oils (\%) of 31 Iranian Achillea millefolium accessions. ${ }^{2}$

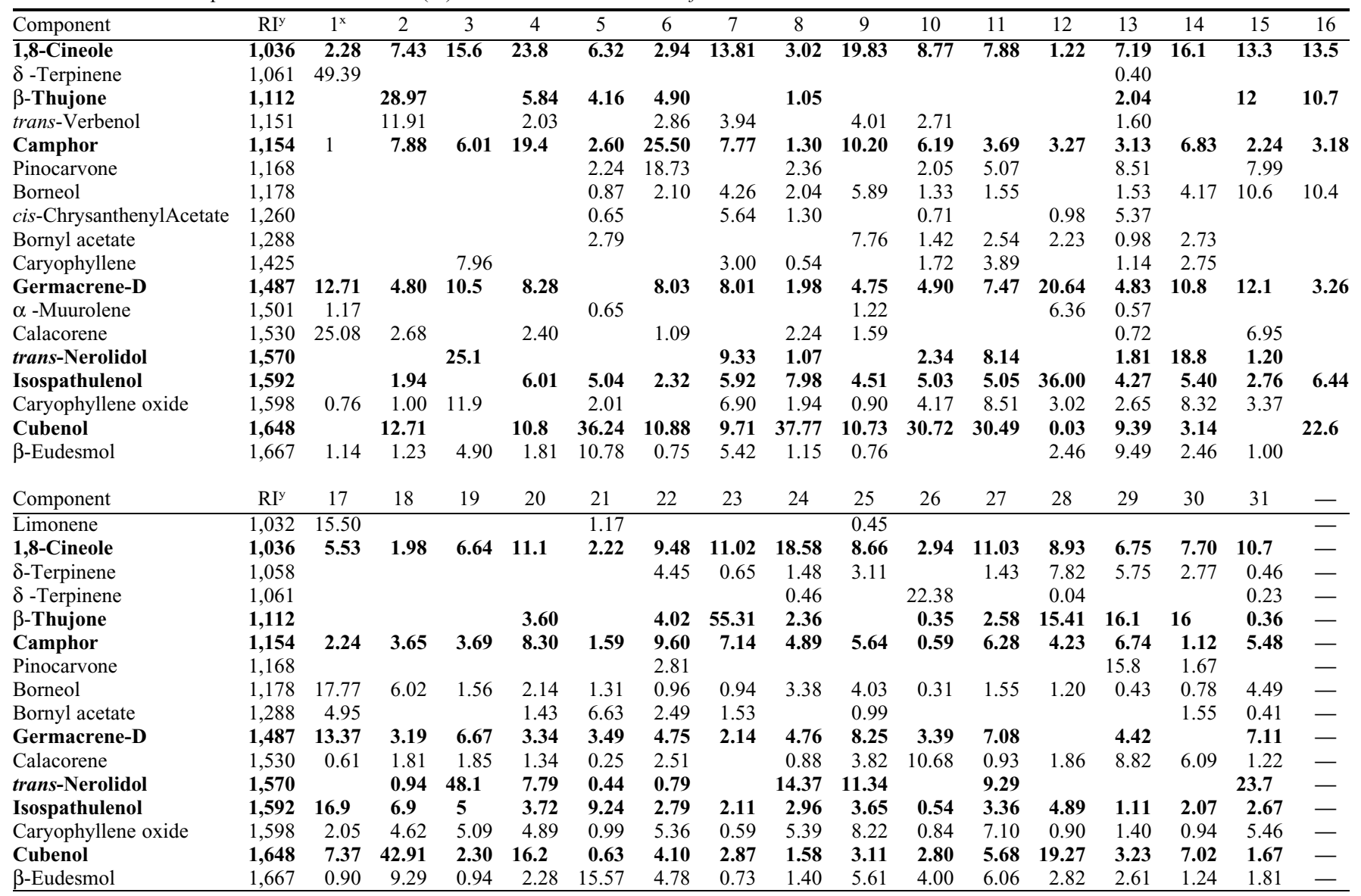

The major compounds are presented as bold.

${ }^{\mathrm{z}}$ The values in the table are percentages of a given constituent in the total oil.

${ }^{\mathrm{y}}$ The data were sorted based on the retention index (RI) of the components.

${ }^{\mathrm{x}} 1$ to 31 are $\mathrm{Am} 1$ to $\mathrm{Am} 31$.

two accessions, and isospathulenol dominated in one accession. 9-epi-(E)-Caryophyllene was observed only in one accession (Am13). Additional unique components in each accessions are shown in Table 3. Dokhani et al. (2005) identified the major compounds of some selected Achillea species in Iran. High interspecies and intraspecies polymorphisms were observed in the studies. In our study, cubenol was the most abundant component. 1,8-Cineole, camphor, terpinolene, borneol, $\gamma$-terpinene, and thujone were the major components of the essential oils in A. millefolium from different regions in North east of Iran (Maz et al., 2013). In the present study, four accessions were from North east of Iran, 1,8Cineole and camphor were just two of the seven main components previously reported. Orav et al. (2007) studied phytochemical analysis of the essential oil of A. millefolium L. from various European countries. Authors indicated that quantitatively the most important components of the plant were bornyl acetate, 1,8-Cineole, sabinene, artemisia ketone, camphor, $\beta$-pinene, linalool, caryophyllene oxide, $\alpha$-thujone, $\beta$-thujone, $\beta$-bisabolol, borneol, fenchyl acetate, (E)- $\beta$-caryophyllene, germacrene $\mathrm{D}, \delta$-cadinol, and chamazulene. According to literature reviews, there were many different reports about the main essential oil components in A. millefolium samples. Information about the factors that control the chemical variability and yield for each medicinal plant is very important but highly understudied. These include physiological variations, environmental factors, geographic variations, genetic factors and evolution, social conditions, and the amount of plant material (Figueiredo et al., 2008).

A. millefolium chemotypes based on their chief components. The cluster analysis was performed using the seven identified main compounds. From this analysis, the Iranian $A$. millefolium accessions were categorized into five groups (Fig. 1). The first group contained of ten accessions (Am25, Am27, Am7, Am15, Am3, Am14, Am31, Am9, Am24, and Am19). The accessions of the first group were rich in 1,8-Cineole and transnerolidol. Am19 accession of this group was separated from others because of the highest percentage of transnerolidol (48.1\%); however, it had the lowest amount of 1,8-Cineole in the group $(6.6 \%)$. The highest amount of caryophyllene oxide $(11.9 \%)$ was observed in Am3 accession. The second group consisted of five accessions. The chief component of the second group was cubenol. Am18 accession had the highest percentage of cubenol $(42.9 \%)$.
Table 4. Principal components databased on 7 major oil compounds of 31 Iranian Achillea millefolium accessions.

\begin{tabular}{llrrr}
\hline & & \multicolumn{3}{c}{ Principal components } \\
\cline { 3 - 5 } Label & Major compound & PC1 & \multicolumn{1}{c}{ PC2 } & PC3 \\
\hline 1 & Germacrene-D & $\mathbf{0 . 9}$ & 0.08 & 0.25 \\
2 & Isospathulenol & $\mathbf{0 . 7 1}$ & -0.49 & 0.09 \\
3 & 1,8-Cineole & -0.19 & $\mathbf{0 . 7 5}$ & -0.09 \\
4 & Trans-nerolidol & 0.28 & $\mathbf{0 . 6 9}$ & -0.42 \\
5 & Cubenol & -0.42 & $\mathbf{- 0 . 6 0}$ & -0.45 \\
6 & Beta-thujone & -0.49 & 0.03 & $\mathbf{0 . 6 0}$ \\
7 & Camphor & -0.10 & 0.15 & $\mathbf{0 . 5 9}$ \\
& Eigenvalue & 1.91 & 1.67 & 1.20 \\
& \% of variance & 27.30 & 23.88 & 16.62 \\
& Cumulative \% & 27.30 & 51.18 & 67.80 \\
\hline
\end{tabular}

The values higher than 0.5 are presented as bold significant.

The third group consisted of Am21, Am26, Am1, Am17, and Am12 accessions. The main components of this group were germacrene-D and isospathulenol. Many unique components were found in the group: Am26 and Am1 accessions were rich in $\gamma$-terpinene and calacorene, Am21 accession was rich in $\beta$-eudesmol and torreyol, and Am17 accession was rich in limonene and borneol. Am4 and Am6 were the only two accessions classified in the fourth group, being rich in both camphor and cubenol. In 
our previous study on genetic variation among the 31 accessions using inter-simple sequence repeat (ISSR) marker, these two accessions were classified at cluster IV (Farajpour et al., 2012), both of them were gathered from the western part of the country. The fifth group comprised ten accessions. The mean percentage of $\beta$-thujone in this group was higher than that of the other groups; however, the group was rich in 1,8-Cineole and cubenol. Am23 had the highest percentage of $\beta$-thujone $(55.3 \%)$.

According to cluster analysis and the concentrations of the seven main compounds in each cluster, the essential oils of Iranian $A$. millefolium accessions were classified into five chemotypes:

1) 1,8-Cineole $(13.4 \%)+$ transnerolidol (16.1\%; 10 accessions)

2) Cubenol (35.6\%; 5 accessions)

3) germacrene-D $(10.7 \%)+$ isospathulenol $(12.5 \% ; 5$ accessions $)$

4) Camphor $(22.5 \%)+$ cubenol $(10.8 \% ; 2$ accessions)

5) 1,8-Cineole $(9.2 \%)+\beta$-thujone $(16.9 \%)+$ cubenol $(10.8 \% ; 9$ accession)

PCA was achieved for the seven main compounds in the essential oils of Iranian $A$. milefollium accessions. The first three principal components (PCs) confirmed $67.8 \%$ of the total variance (Table 4). The first PC confirmed for $27.3 \%$ of the total variance and correlated positively with germacrene-D (0.9) and isospathulenol (0.71). 1,8-Cineole $(0.75)$ and transnerolidol $(0.69)$ components showed a positive, and cubenol $(-0.6)$ indicated a negative correlation but with the second PC. The third PC confirmed more than $16 \%$ of the total variance and correlated positively with $\beta$-thujone (0.6) and camphor (0.59). Because all accessions were cultivated in the same location, the main contributor to variation among the accessions is genetic factors. Thus, it seems the first factor (PC1) is a genetic factor. The $\mathrm{PC} 1$ was highly correlated with germacrene-D and isospathulenol; hence, the two components are under more genetic control than the other components.

\section{Conclusion}

Herein, a comprehensive phytochemical analysis of essential oils among Iranian $A$. millefolium accessions was performed. The result of the present study showed that there was a high phytochemical and essential oil variation among 31 Iranian A. millefolium accessions. The main components among the studied accessions were 1,8-Cineole, 1.2$19.8 \%$; $\beta$-thujone, $0.6-55.3 \%$; camphor, $0.6-25.5 \%$; germacrene-D, 2-20.6\%; transnerolidol, $0.4-48.1 \%$; isospathulenol, 0.5 $36 \%$; and cubenol, $0.1-42.9 \%$. The result revealed five chemotypes in Iranian $A$. millefolium accessions according to main compounds including high 1,8-Cineole/transnerolidol, high cubenol, high germacrene-D/ isospathulenol, high camphor/cubenol, and high 1,8-Cineole/ $\beta$-thujone/cubenol.

\section{Literature Cited}

Afsharypuor, S., S. Asgary, and G.B. Lockwood. 1996. Volatile constituents of Achillea millefolium L. ssp. millefolium from Iran. Flavour Fragrance J. 11(5):265-267.

Anwar, F. 2009. Changes in composition and antioxidant and antimicrobial activities of essential oil of fennel (Foeniculum vulgare Mill.) fruit at different stages of maturity. J. Herbs Spices Med. Plants 15:1-16.

Benedek, B., B. Kopp, and M.F. Melizg. 2007. Achillea millefolium L.S. 1. Is the antiinflammatory activity mediated by protease inhibition. J. Ethnopharmacol. 113:312-317.

Dehghan, G. and F. Elmi. 2015. Essential oil combination of three species of Achillea growing wild in East Azarbayjan-Iran. Adv. Herb. Med. 1(1):22-28.

Dokhani, S., T. Cottrell, J. Khajeddin, and G. Mazza. 2005. Analysis of aroma and phenolic components of selected Achillea Species. Plant Foods Hum. Nutr. 60:55-62.

Ebrahimi, M., M. Farajpour, H. Hadavand, K Bahmani, and F. Khodaiyan. 2012. Essential oil variation among five Achillea millefolium ssp. elbursensis collected from different ecological regions of Iran. Ann Biol Res. 3(7):3248-3253.

Farajpour, M., M. Ebrahimi, R. Amiri, R. Golzari, and S. Sanjari. 2012. Assessment of genetic diversity in Achillea millefolium accessions from Iran using ISSR marker. Biochem. Syst. Ecol. 43:73-79.

Farnsworth, N.R. 1966. Biological and phytochemical screening of plants. J. Pharm. Sci. 55(3):225-276.
Figueiredo, A.C., J.G. Barroso, L.G. Pedro, and J.J. Scheffer. 2008. Factors affecting secondary metabolite production in plants: Volatile components and essential oils. Flavour Fragrance J. 23(4):213-226.

Gudaityte, O. and P.R. Venskutonis. 2007. Chemotypes of Achillea millefolium transferred from 14 different locations in Lithuania to the controlled environment. Biochem. Syst. Ecol. 35:582-592.

Jaimand, K., M.B. Rezaee, and V. Mozaffarian. 2006. Chemical constituents of the leaf and flower oils from Achillea millefolium ssp. elbursensis Hub.-Mor. from Iran rich in chamazulene. J. Essent. Oil Res. 18(3):293-295.

Judzentiene, A. 2016. Atypical chemical profiles of wild yarrow (Achillea millefolium L.) essential oils. Rec. Nat. Prod. 10(2):262-268.

Maz, M., S.Z. Mirdeilami, and M. Pessarakli. 2013. Essential oil composition and antibacterial activity of Achillea millefolium L. from different regions in North east of Iran. J. Med. Plants Res. 7(16):1063-1069.

Mazandarani, M., B. Behmanesh, M.B. Rezaei, and E.O. Ghaemi. 2007. Ecological factors, chemical composition and antibacterial activity of the essential oil from Achillea millefolium L. in the north of Iran. Planta Med. 73(9):P179.

Orav, A., E. Arak, and A. Raal. 2006. Phytochemical analysis of the essential oil of Achillea millefolium L. from various European Countries. Nat. Prod. Res. 20(12):1082-1088.

Naeini, A., A.R. Khosravi, M. Chitsaz, H. Shokri, and M. Kamlnejad. 2009. Anti-Candida albicans activity of some Iranian plants used in traditional medicine. J. Med. Mycol. 19 (3): $168-172$.

Pandith, J.I. 2012. Phytochemical screening of certain plant species of Agra City. J. Drug Deliv. Ther. 2(4):135-138.

Steel, R.G.D. and J.H. Torrie. 1980. Principles and procedures of statistics: A biometrical approach. McGraw-Hill, Inc., NY.

Sevindik, E., Z.T. Abacı, C. Yamaner, and M. Ayvaz. 2016. Determination of the chemical composition and antimicrobial activity of the essential oils of Teucrium polium and Achillea millefolium grown under North Anatolian ecological conditions. Biotechnol. Biotechnol. Equip. 30(2):375-380.

Stevanovic, Z.D., D. Pljevljakušic, M. Ristic, I. Šoštaric, M. Kresovic, I. Simic, and S. Vrbnièanin. 2015. Essential oil composition of Achillea millefolium agg. populations collected from saline habitats in serbia. J. Essent. Oil Bear. Plants 18 (6):1343-1352. 